\title{
Short Note \\ Source Parameters of the Shallow 2012 Brawley Earthquake, Imperial Valley
}

\author{
by Risheng Chu and Don V. Helmberger
}

\begin{abstract}
Resolving earthquake parameters, especially depth, is difficult for events occurring within basins because of issues involved with separating source properties from propagational path effects. Here, we demonstrate some advantages of using a combination of teleseismic and regional waveform data to improve resolution following a bootstrapping approach. Local $S S-S$ differential arrivals from a foreshock are used to determine a local layered model which can then be used to model teleseismic depth phases: $p P, s P$, and $s S$. Using the cut-and-paste (CAP) method for which all strike $(\theta)$, dip $(\delta)$, rake $(\lambda)$, and depth variations are sampled for several crustal models. We find that regional data prove the most reliable at fixing the strike, whereas the depth is better constrained by teleseismic data. Weighted solutions indicate a nearly pure strike-slip mechanism $\left(\theta=59^{\circ} \pm 1^{\circ}\right)$ with a centroid depth of about $4.0 \mathrm{~km}$ and an $M_{\mathrm{w}}$ of 5.4 for the mainshock of the 2012 Brawley earthquake.
\end{abstract}

Online Material: Figures showing examples of waveform fits, comparison of synthetic teleseismic waveforms using different grid sizes in the FD calculation, effect of soft sediment on teleseismic Green's functions, and sensitivity of regional and teleseismic data on the focal mechanisms.

\section{Introduction}

Recent upper mantle studies involving USArray data have taken advantage of $P$ and $S H$ waveforms from regional earthquakes (Chu, Schmandt, Helmberger, 2012). For this approach to be effective requires the identification of depth phases which can interfere with triplication arrivals. Generally, we generate two solutions, one based on regional data and the other on teleseismic body waves ( $P$ and $S H$ waves). These solutions usually agree with each other (Chu, Schmandt, Helmberger, 2012). But for earthquakes in the Imperial Valley, the depths appear different because of the deep sediment basin.

The southern San Andreas fault system has a long history of significant earthquakes including the recent 2010 $M_{\mathrm{w}} 7.2$ El Mayor-Cucapah event (Wei et al., 2011). The most recent burst of earthquakes occurred on 26 August 2012 with the largest one having $M_{\mathrm{w}} 5.4$. The hypocenter is indicated in Figure 1 along with early aftershock locations from Hauksson et al. (2012). Note the fine structure with rapidly varying sedimentary depths (Magistrale et al., 2000). The details of this structure are under study (Delph et al., 2011), but at present not well defined. Thus, we propose a reasonable way to approach such events in defining useful point-source parameters that can be used for global modeling of seismic structures, evaluating possible earthquake triggering of geothermal activities, and assessing seismic hazards.

The Brawley mainshock is well recorded by USArray as well as over 100 regional broadband stations within a distance of $500 \mathrm{~km}$ and more than 80 teleseismic broadband stations mainly on the tangential component (Fig. 2a,b). This dense station coverage is ideal for retrieving accurate source parameters using the cut-and-paste (CAP) methodology. The original CAP breaks long-period regional waveform data into $P_{n l}$ wave and surface-wave segments and shifts them independently to find the best waveform fits (Zhao and Helmberger, 1994; Zhu and Helmberger, 1996). A modification of the method for teleseismic waveform data has been successfully applied to earthquakes involving USArray and beneath Japan (Chu, Schmandt, Helmberger, 2012; Chu, Wei, et al. 2012; Zhan et al., 2012). Because the crustal structures in the source and receiver regions are decoupled teleseismically, they are allowed to be distinct. This feature proves especially valuable for exploiting depth phases for shallow events in basin structures such as this Brawley event.

Because regional waves travel essentially horizontally and teleseismic body waves have nearly vertical ray paths, regional and teleseismic CAP inversions have distinct depth 


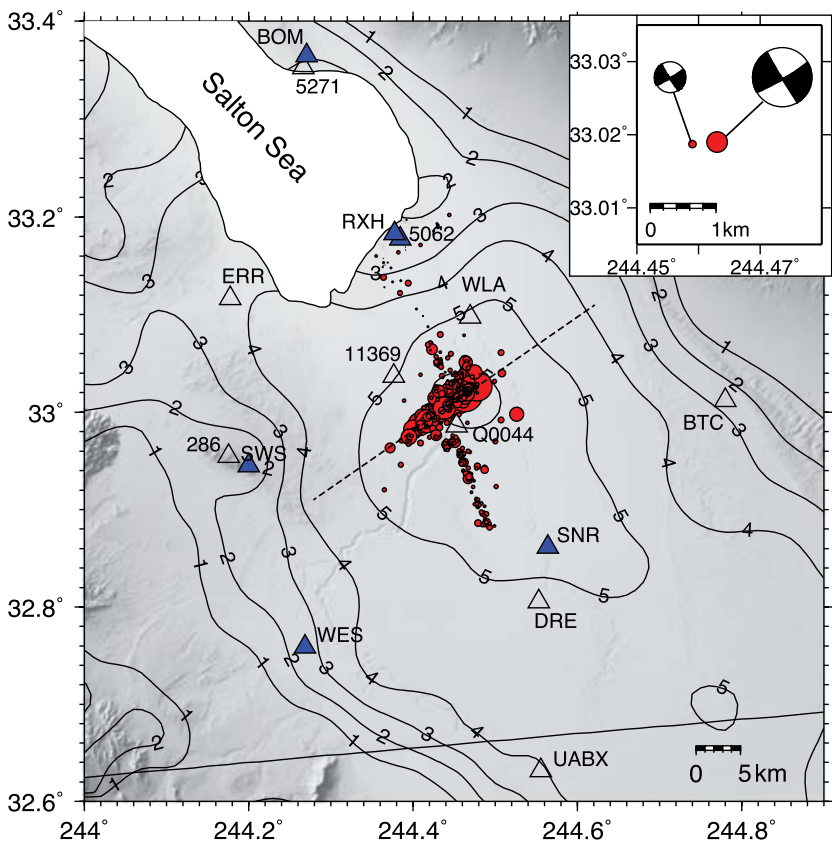

Figure 1. Hypocenters of the 26 August 2012 Brawley earthquake swarm. Solid dots denote relocated earthquakes from Hauksson et al. (2012). The contours show the depth of basement rocks with depth labeled at an interval of $1 \mathrm{~km}$ (Magistrale et al., 2000). Solid triangles are local seismic stations used in this study. The dashed line denotes the inverted strike direction. The inset shows the locations and focal mechanisms of the $M_{\mathrm{w}} 3.9$ foreshock and the mainshock. The color version of this figure is available only in the electronic edition.

sensitivity to the velocity structures. To demonstrate this sensitivity, we inverted the source parameters (Fig. 2) using three different velocity models as presented in Figure 3a, the standard southern California velocity model SC (Dreger and Helmberger, 1993), the Imperial Valley model IV (Tian et al., 2010), and the Salton Trough model ST derived in this study. Both regional and teleseismic inversions indicate similar focal mechanisms, and both inversions have good waveform fits with cross-correlation coefficients (CC) larger than 80\% (Fig. 2). Figure 2a displays the CCs of regional 20-s Love waves between data and synthetics for the SC model and Figure $2 \mathrm{~b}$ shows the $\mathrm{CCs}$ for the 5-s teleseismic $\mathrm{SH}$ waves for the ST model. Some examples of regional waveform fits are displayed in (E) Figure S1, available in the electronic supplement to this paper. Because of the strike-slip radiation pattern, stations in the $S H$ nodal directions have relatively lower CCs, e.g., IRM, 214A, and SDD (Fig. 2a). The low CCs appear to be caused by Rayleigh-wave contaminations, in that, Rayleigh waves are at their strongest and Loves waves at their weakest, which is commonly observed (Scrivner and Helmberger, 1999). Such feature is especially obvious for strike-slip earthquakes in the North American craton (Chu, Schmandt, Helmberger, 2012).

Note that at regional distances (Fig. 2a) most of the stations are located outside of the basin where the standard
$\mathrm{SC}$ model gives the best waveform fits with a depth of $5.5 \mathrm{~km}$ and an $M_{\mathrm{w}}$ of 5.4. However, because of the 3D nature of the source region, the minimum of the misfit curve is not well defined (Fig. 2c). Velocity models IV and ST yield similar earthquake depths, but smaller magnitude because of the lower velocities at the receivers. All three teleseismic inversions have similar magnitude, but the depth varies significantly, which indicates that teleseismic inversions have more sensitivity to the velocity structure, and potentially better depth resolution if the structure is known (Fig. 2d). In order to obtain a reliable depth for the Brawley earthquake, we need a refined 1D shear-velocity model for the source region. Therefore, we modeled regional waveforms with distances less than $50 \mathrm{~km}$ (within the basin) from an $M_{\mathrm{w}} 3.9$ foreshock and obtained a $1 \mathrm{D}$ velocity basin model ST for the Salton Trough (Fig. 1).

\section{D Salton Trough Model}

We start from the standard southern California velocity model SC and impose a 1D basin structure on the top (Fig. 3a). The thickness of the basin is set at $5.5 \mathrm{~km}$ based on the depth of the basement rocks in the Salton Trough (Fig. 1; Magistrale et al., 2000). To reduce the number of free parameters in the model construction, we assume that the shear velocities change linearly with depth, similar to the grid-search approach of Chu, Schmandt, Helmberger (2012). Only two variables were evaluated through the grid search, the top and bottom velocity of the basin.

In order to minimize the 3D effect of the basin structure and avoid clipping of waveforms due to strong motions, we modeled regional data with distances between $10 \mathrm{~km}$ and $50 \mathrm{~km}$ from an $M_{\mathrm{w}} 3.9$ foreshock, which is about $1 \mathrm{~km}$ to the west of the mainshock according to the relocated catalog (Fig. 1; Hauksson et al., 2012). At this distance, two additional arrivals can be seen on the waveform following the direct $S$ waves due to the free surface, $s S$ reflected near the earthquake, and $S S$ reflected at the mid-point (Fig. 3b,c). The differential travel times between $s S$ and $S$ depend strongly on the earthquake depth, whereas $S S-S$ travel times are mainly affected by the velocity structure above the earthquake, which is ideal for our modeling purposes (Fig. 3d). Multiple surface reflections of $P$ waves have been observed and used to study $P$-velocity structure and earthquake depth in the same area (Mori, 1991). After examining 12 stations, we found 6 waveforms with clear SS phases sampling the various azimuths. We modeled these waveforms in displacement after applying a bandpass filter of $0.1-2.0 \mathrm{~Hz}$ (Fig. 3b). These waveforms are aligned at the arrivals of direct $S$. Our best model has the lowest velocity of $0.6 \mathrm{~km} / \mathrm{s}$, and the velocity slope agrees with the result of Tian et al. (2010), which is derived from ambient noise studies (Fig. 3a).

To test the effects of the basin structure and validate our modeling on the $S S-S$ travel times, we constructed a 2D basin model using SC as the background model (Fig. 4a). 

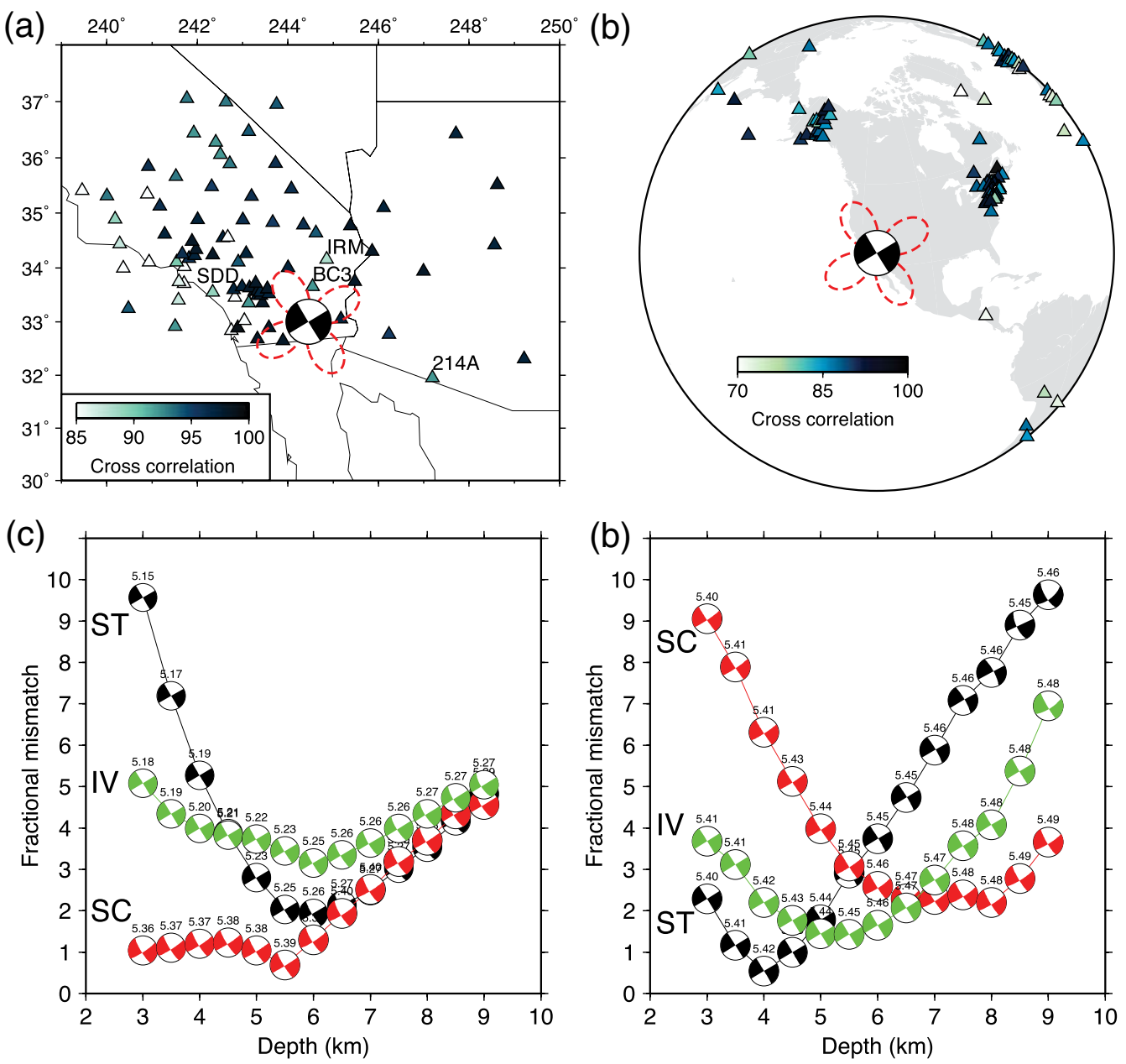

Figure 2. Regional and teleseismic CAP inversions. (a) and (b) display cross-correlation coefficient (CC) for regional inversion using SC model and teleseismic inversion using ST model, respectively. We have included the $S H$ radiation pattern as the dashed curves. (c) and (d) show the misfits as a function of centroid depth for the southern California model SC, the Imperial Valley model IV, and the Salton Trough model ST for the regional and teleseismic inversions, respectively. Note strong minima found for the ST model, especially at teleseismic distances. Teleseismic $t^{*}$ for $P$ and $S H$ waves are 0.8 and $3.2 \mathrm{~s}$, respectively (Chu, Schmandt, Helmberger, 2012). The color version of this figure is available only in the electronic edition.

The depth of the basin is obtained from the depth of the basement rock in Southern California Earthquake Center Community Velocity Model along the strike direction (Magistrale et al., 2000). A GPU version of the 8th order staggeredgrid 2D finite difference code is used for the numerical computation (Li et al., 2012). 1D synthetic waveforms are obtained through the frequency-wavenumber integration (Zhu and Rivera, 2002). The results indicate that the 2D basin structure has minimal effect on the $S S-S$ travel times for stations inside and outside of the basin (Fig. 4b). The large delay in $s S$ and $S S$ is caused by the very slow velocities near the surface bounce. Thus as long as these interactions are within the basin, the combined pulse will be late as observed. In short, for stations located at the edge of the basin, for example, from 30 to $40 \mathrm{~km}$, the recorded waveforms are somewhat distorted, but the $S S-S$ travel times remain about the same.

We also propagated the $P$ and $S H$ wave fields for the 1D and $2 \mathrm{D}$ basins to triplication and teleseismic distances. The mantle structure is taken from AK135 (Kennett et al., 1995). The predicted synthetics at teleseismic distances are displayed in Figure 4c for $S H$ and Figure 4d for $P$ waves. Although the extra coda caused by basin-edge effects can be seen at some takeoff angles, such as $26^{\circ}$ in $\mathrm{SH}$, the synthetics appear 1D-like at large distances. These calculations were done at $0.2-\mathrm{km}$ grid so that the edges of the basin would be relatively smooth. A larger grid does display a strong coda (see (E) Fig. S2, in electronic supplement), indicating that sharp walls are needed to produce significant teleseismic signals but they will be late enough to be avoided at least for short duration events. Another issue involving the teleseismic waveforms is the relative ratio of depth phases. Although the phase $s P$ is the strongest arrival for hard-rock source conditions, we expect a much weaker arrival in this case because the $s P$ conversion is weak. This feature can be easily seen in synthetics as displayed in (E) Figure S3 (in electronic supplement). In summary, it appears that the 
(a)

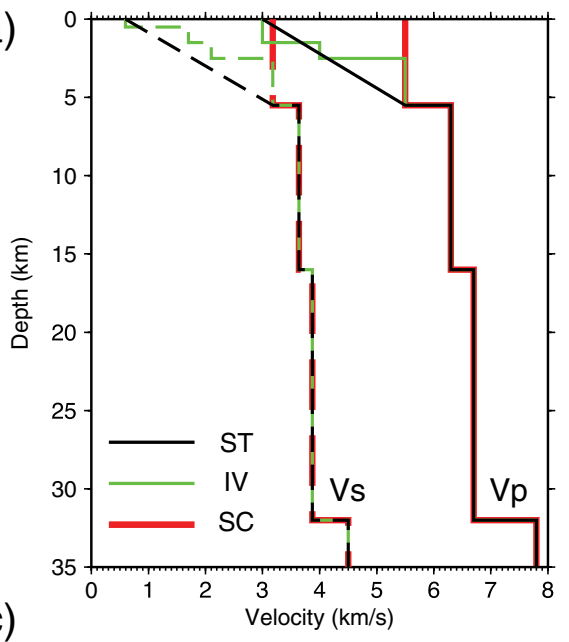

(C)

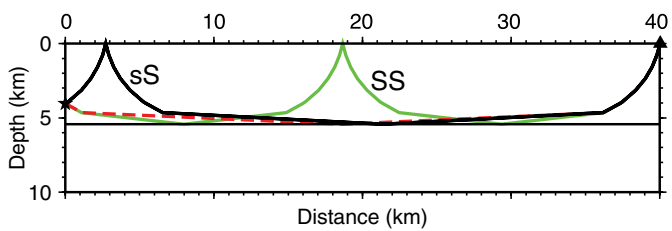

(b)

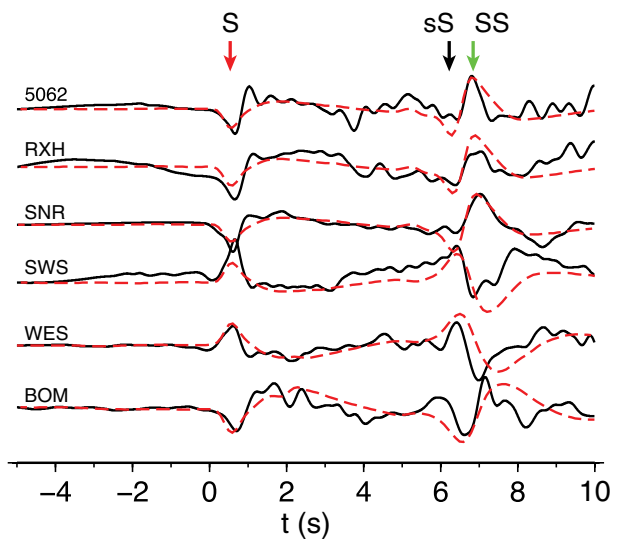

(d)

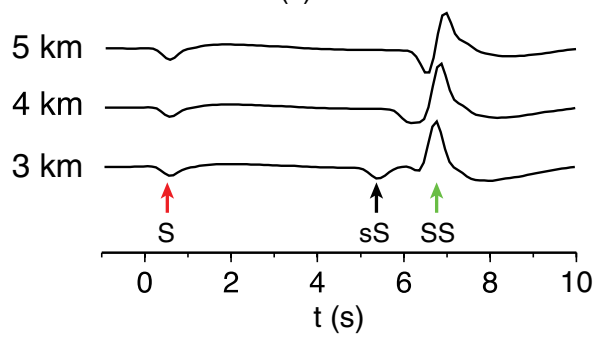

Figure 3. 1D Salton Trough shear-velocity model. (a) A comparison of 1D velocity models between southern California model SC, Imperial Valley model IV, and Salton Trough model ST. Because of the deep basin structure, multiple surface reflections $s S$ and $S S$ are observed following the direct $S$. These three arrivals are indicated by arrows in (b) and their ray paths are given in (c). Synthetic waveforms for events with depth at $3 \mathrm{~km}, 4 \mathrm{~km}$, and $5 \mathrm{~km}$ suggest that $s S$ is easily affected by earthquake depth and $S S$ is determined mainly by the basin velocity structure (d). Synthetics from velocity model ST (dashed lines), bandpass filtered between 0.1 and $2.0 \mathrm{~Hz}$, is plotted against tangential displacement data in (b). Both data and synthetics are aligned at the arrivals of the direct $S$. The color version of this figure is available only in the electronic edition.

teleseismic data have some advantages and should be used in conjunction with regional observations to estimate source properties.

With model ST, the Brawley earthquake is estimated at a centroid depth of $\sim 4.0 \mathrm{~km}$. We next assess the accuracy and stability of the regional and teleseismic inversions of the mainshock through a bootstrapping approach, and a joint inversion of regional and teleseismic waveform data is performed.

\section{Bootstrapping of CAP Inversions}

Because of the non-linear characteristics of waveform inversion, it is not trivial to assess the accuracy and stability of these inversions. Here, we use the bootstrapping method to derive estimates of confidence intervals. Following this approach, the $n$ records used in the inversion are resampled $m$ times, each with the same number of total records $n$, but some are duplicated whereas some are not sampled. Basically, each observation is selected separately at random from the original dataset. Then we analyze each sample in the same way as the original dataset to estimate the focal mechanism. The confidence intervals and other statistic quantities can be estimated from these $m$ results. This approach has been successfully applied to obtain high-resolution mechanisms for the Tohoku area (Zhan et al., 2012). Figure 5 displays the histogram of strike, dip, and rake with $m=500$ resamples for four inversions. Note that the CAP method is particularly effective in such an analysis in that each observed waveform is compared against a synthetic grid $(\theta, \delta, \lambda)$ with a $\mathrm{CC}$ assigned and stored. Thus, it requires just adding up these misfit errors in obtaining individual parameter samples. Thus, the means and standard deviations are also calculated and shown assuming Gaussian distributions. Nodal planes (black lines) and pressure/tension (P/T) axes (solid and open circles) of the 500 focal mechanisms are also shown together with nodal planes (thick lines) and P/T axes (diamonds and triangles) of the focal mechanism from the original dataset (Fig. 5). Apparently for this particular earthquake, the focal mechanism is well resolved to the order of several degrees for the fault-orientation parameters.

However, regional and teleseismic inversions have different constraints on the strike, dip, and rake. As discussed earlier, the strike in the regional inversion is mainly determined by the nodal directions of $P$ and $S H$ waves, and the azimuthal coverage of dense regional stations is given in Figure 2a. Therefore, the bootstrapping of regional inversion shows an excellent constraint on the strike within $3^{\circ}$, but the distribution of dip and rake varies by as much as $20^{\circ}$ (Fig. 5a). For teleseismic inversion, the strike is constrained by the relative amplitude change of $S H$ waves. Most of the stations are located along the maximum directions of $S H$ waves in northeast United States and Alaska. Because of 3D effect of these paths, the amplitude can vary as discussed in Zhan 

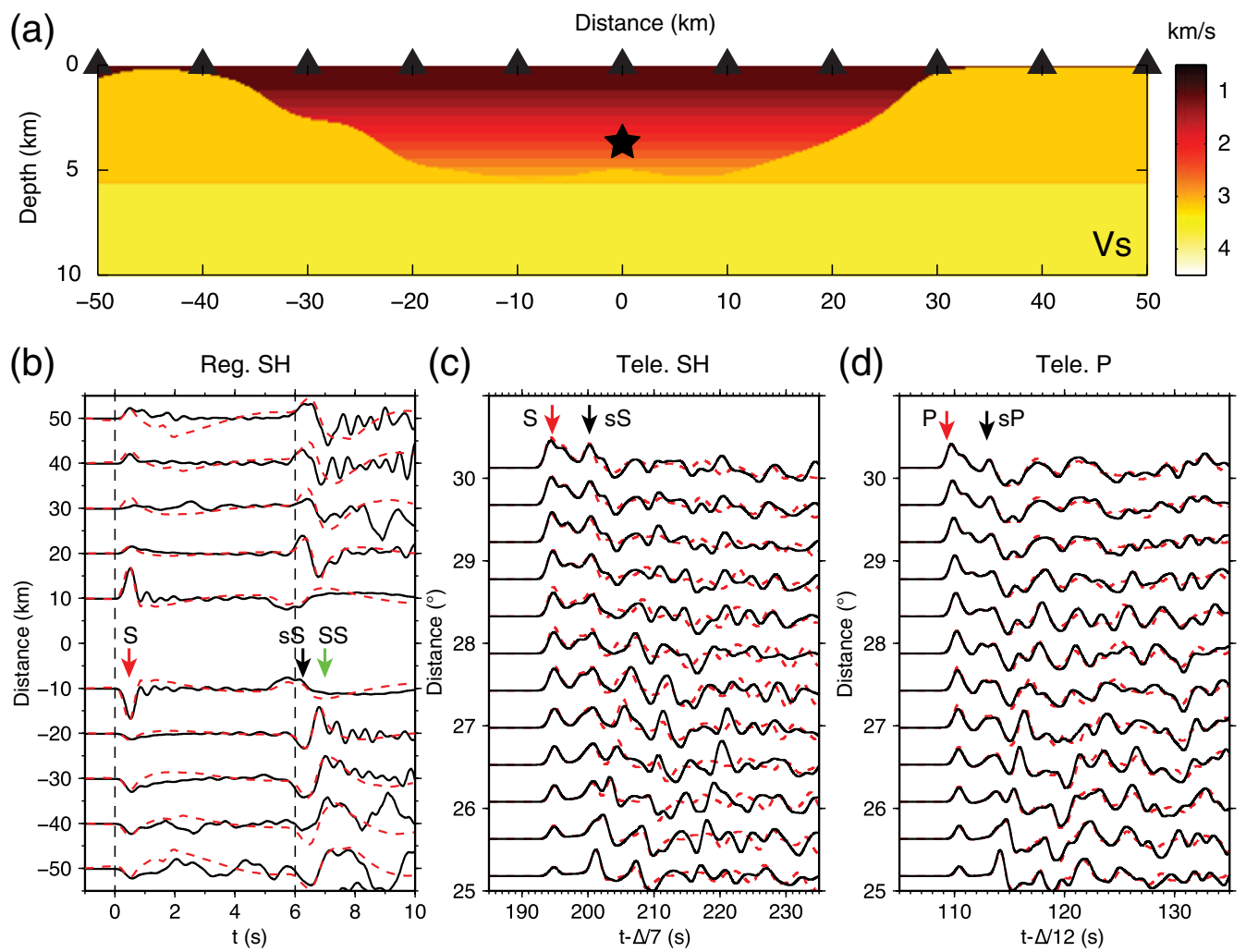

Figure 4. Effects of 2D basin structure on regional and teleseismic waveforms. (a) The basin structure is constructed using the depth of basement rocks along the strike from Magistrale et al. (2000; Fig. 1). Inside the basin, the velocities are those from model ST. The background velocities are the models SC for the crust and AK135 for the mantle (Kennett et al., 1995). The star represents the hypocenter of the Brawley earthquake. (b) Comparison of regional SH waves from 2D basin structure (black lines) and those from 1D model SC (dashed lines). All synthetics are bandpass filtered using corner frequencies of 0.1 and $2.0 \mathrm{~Hz}$. The direct $S$ and its surface reflections $s S$ and $S S$ are labeled. (c) and (d) show comparisons of teleseismic $S H$ and $P$ waves from 2D (black lines) and 1D (dashed lines) basin structures. The color version of this figure is available only in the electronic edition.

et al. (2012), which will give a poor constraint on the strike (Fig. 5b). The teleseismic inversion also involves the direct $S$ and its depth phase $s S$, which provide two sampling points on the focal sphere for each station. Thus the dip and rake are well resolved.

The regional inversion has strike $/ \mathrm{dip} / \mathrm{rake}=$ $58^{\circ} / 87^{\circ} /-7^{\circ}$, whereas the teleseismic inversion has $59^{\circ} / 90^{\circ} / 1^{\circ}$. The largest difference between them is the rake angle. We calculate regional Love waves and teleseismic $\mathrm{SH}$ waves using these two solutions and compare them with observed data (see (E) Fig. S4, in electronic supplement). Regional data display little difference between these two solutions. For teleseismic data, the teleseismic solution has relatively larger CCs than regional solution, which suggests that teleseismic data can help determine the dip and rake quite accurately if the strike is constrained.

Regional data determine the strike and teleseismic data provide the dip and rake. Thus, the question is whether we can determine an optimal result by using a joint inversion? Because the amplitude of teleseismic data is negligibly small compared to the amplitude of regional data, we need to balance the weighting between these two datasets (Chen et al., 2012). An easy way is to equalize the root mean square of waveform fits between regional CAP and teleseismic CAP. By this approach, the strike, dip, and rake are all constrained within a few degrees (Fig. 5c). If we increase the weighting of teleseismic data by a factor of 2 , the distributions of dip and rake becomes even more compact, but the distribution of strike gets worse as expected (Fig. 5d).

In summary, we derived a 1D shear-velocity model for the Salton Trough region by modeling multiple surface reflections of $S$ wave. With this velocity model, teleseismic waveform modeling estimates the 26 August 2012 Brawley earthquake at a centroid depth of about $4.0 \mathrm{~km}$. We obtained focal mechanisms using regional and teleseismic waveform data and assessed the accuracy and stability of these solutions through the bootstrapping approach. Joint inversions of regional and teleseismic data are also performed, which suggest a pure strike-slip mechanism.

\section{Data and Resources}

Waveform data used in this study are obtained through IRIS Data Management Center (http://www.iris.edu/data, last accessed August 2012). 

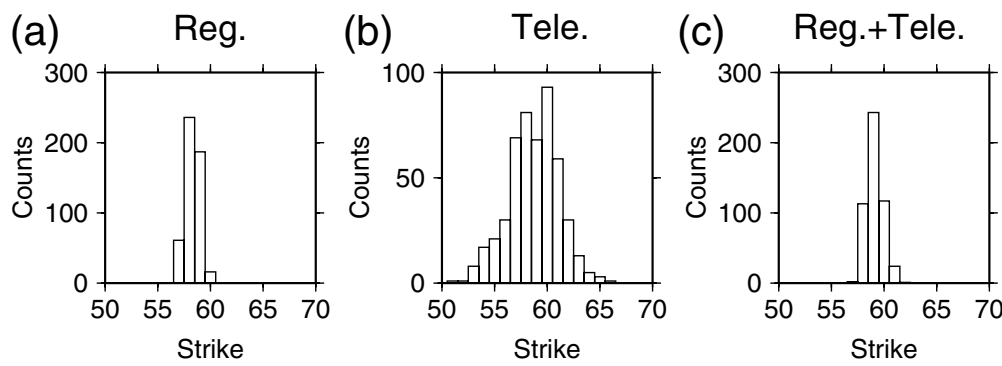

(d) Reg. $+2{ }^{*}$ Tele.
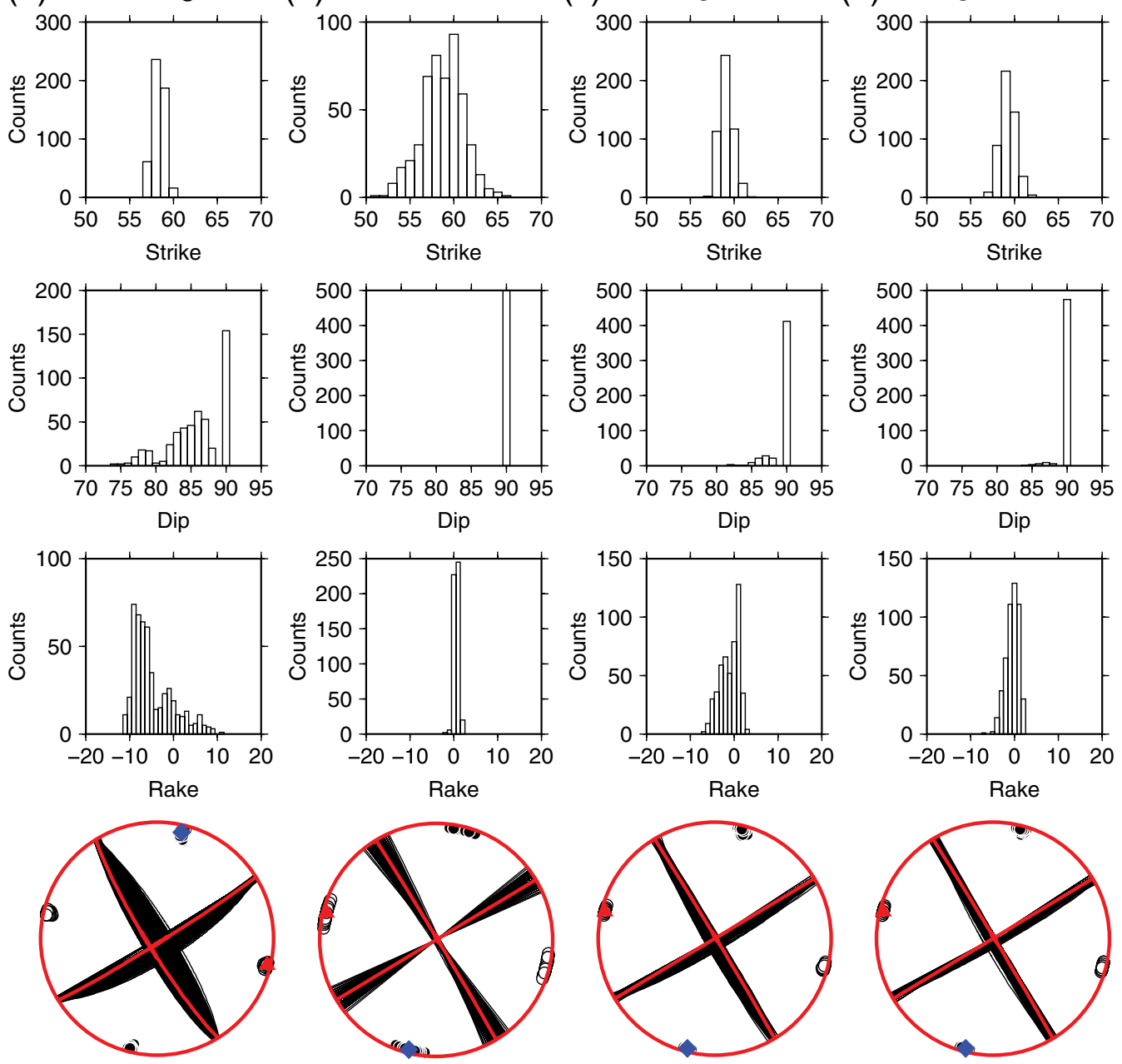

Figure 5. Bootstrapping of CAP inversions. Distribution of strike, dip, and rake from 500 solutions are displayed for (a) regional and (b) teleseismic inversions, respectively. Two joint inversions using both regional and teleseismic data are displayed in (c) and (d) with different weight of teleseismic data. Nodal planes (black lines) and P/T axes (solid and open circles) of the 500 mechanisms are also shown together with nodal planes (thick lines) and $\mathrm{P} / \mathrm{T}$ axes (diamonds and triangles) of the mechanism from the original dataset. The color version of this figure is available only in the electronic edition.

\section{Acknowledgments}

We thank Associate Editor Cezar I. Trifu and an anonymous reviewer for the valuable comments that greatly improved the manuscript. We thank Egill Hauksson for providing his relocated earthquake hypocenters. This work is partially supported by the Gordon and Betty Moore Foundation through the Tectonics Observatory at California Institute of Technology. Additional support came from USGS through Award Number G12AP20072. This is Contribution Number 10084 of Seismological Laboratory, California Institute of Technology.

\section{References}

Chen, W., S. Ni, Z. Wang, X. Zeng, and S. Wei (2012). Joint inversion with both local and teleseismic waveforms for source parameters of the 2010 Kaohsiung earthquake, Chin. J. Geophys. 55, no. 7, 23192328 (in Chinese).

Chu, R., B. Schmandt, and D. V. Helmberger (2012). Upper mantle $P$ velocity structure beneath the Midwestern United States derived from triplicated waveforms, Geochem. Geophys. Geosyst. 13, no. Q0AK04, 21 pp., doi: 10.1029/2011GC003818.
Chu, R., S. Wei, D. V. Helmberger, Z. Zhan, L. Zhu, and H. Kanamori (2012). Initiation of the great $M_{\mathrm{w}} 9.0$ Tohoku-Oki earthquake, Earth Planet. Sci. Lett. 308, no. 3, 277-283.

Delph, J., J. A. Hole, G. S. Fuis, J. M. Stock, and M. J. Rymer (2011). The Salton seismic imaging project: Seismic velocity structure of the Brawley seismic zone, Salton Buttes and Geothermal Field, Salton Trough, California (abstract T33G-2497), Presented at 2011 Fall Meetings, $A G U$, San Francisco, California, 5-9 December.

Dreger, D. S., and D. V. Helmberger (1993). Determination of source parameters at regional distances with three-component sparse network data, J. Geophys. Res. 98, no. B5, 8107-8125.

Hauksson, E., J. Stock, R. Bilham, M. Boese, X. Chen, E. J. Fielding, J. Galetzka, K. W. Hudnut, K. Hutton, L. M. Jones, H. Kanamori, P. M. Shearer, J. Steidl, J. Treiman, S. Wei, and W. Yang (2012). Report on the August 2012 Brawley earthquake swarm in Imperial Valley, Southern California, Seismol. Res. Lett (in press).

Kennett, B., E. R. Engdahl, and R. Buland (1995). Constraints on seismic velocity in the Earth from travel times, Geophys. J. Int. 122, 108-124.

Li, D., D. V. Helmberger, and R. W. Clayton (2012). Point source seismogram using 2D finite difference method, Seismol. Res. Lett. 83, no. 2, 363 pp. 
Magistrale, H., S. Day, R. W. Clayton, and R. Graves (2000). SCEC southern California reference 3D seismic velocity model Version 2, Bull. Seismol. Soc. Am. 90, no. 6B, S65-S76.

Mori, J. (1991). Estimates of velocity structure and source depth using multiple $P$ waves from aftershocks of the 1987 Elmore Ranch and Superstition Hills, California, earthquakes, Bull. Seismol. Soc. Am. 81, no. 2, 508-523.

Scrivner, C. W., and D. V. Helmberger (1999). Variability of ground motions in southern California: Data from the 1995 to 1996 Ridgecrest sequence, Bull. Seismol. Soc. Am. 89, 626-639.

Tian, X., S. Wei, Z. Zhan, E. J. Fielding, and D. V. Helmberger (2010) Modeling events in the lower Imperial Valley basin (abstract S53C-1989) Presented at 2010 Fall Meeting, AGU, San Francisco, California, 13-17 December.

Wei, S., E. J. Fielding, S. Leprince, A. Sladen, J.-P. Avouac, D. V. Helmberger, E. Hauksson, R. Chu, M. Simons, K. Hudnut, T. Herring, and R. Briggs (2011). Superficial simplicity of the 2010 El MayorCucapah earthquake of Baja California in Mexico, Nat. Geosci. 4, no. $9,615-618$.

Zhan, Z., D. V. Helmberger, M. Simons, H. Kanamori, W. Wu, N. Cubas, Z. Duputel, R. Chu, V. C. Tsai, J.-P. Avouac, K. Hudnut, S. Ni,
E. Hetland, and F. Ortega Culaciati (2012). Anomalously steep dips of earthquakes in the 2011 Tohoku-Oki source region and possible explanations, Earth Planet. Sci. Lett. 353, 121-133.

Zhao, L., and D. V. Helmberger (1994). Source estimation from broadband regional seismograms, Bull. Seismol. Soc. Am. 84, 91-104.

Zhu, L., and D. V. Helmberger (1996). Advancement in source estimation techniques using broadband regional seismograms, Bull. Seismol. Soc. Am. 86, 1634-1641.

Zhu, L., and L. A. Rivera (2002). A note on the dynamic and static displacements from a point source in multi-layered media, Geophys. J. Int. 148, 619-627.

Seismological Laboratory

California Institute of Technology

1200 E. California Blvd., MC 252-21

Pasadena, California 91125

chur@gps.caltech.edu

Manuscript received 1 November 2012 